\title{
ESTIMATION OF REPAIR COSTS OF INDIVIDUAL NON-DOMESTIC BUILDINGS DAMAGED BY FLOODS
}

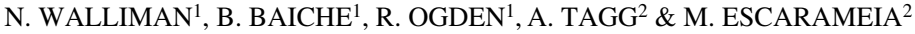 \\ ${ }^{1}$ School of Architecture, Oxford Brookes University, Oxford, UK. \\ ${ }^{2} \mathrm{HR}$ Wallingford, Oxfordshire, UK.
}

\begin{abstract}
It is evident that there is no established flood damage prediction tool for individual non-domestic buildings that can account in any detail for their different types of construction. Unlike domestic buildings, non-domestic buildings often feature several different types of construction within the same premises. This absence makes it difficult for building owners and designers to calculate what appropriate measures should be taken to enhance resilience against floods.

This paper, developed in the context of the European Community FP7 project FloodProBE, and presented at the Sustainable City 2012 Conference, discusses the current estimation methods used in the UK, Germany, USA and Australia, and suggests a way to improve on these by devising a tool capable of estimating damage to individual non-domestic buildings. Standard damage and repair parameters are investigated and the major variables are considered - those related to the flood event such as overfloor depth, velocity, rate of rise, debris, contaminants, frequency and duration of inundation and timing, and those relate to the building characteristics, such as structure, construction, materials and their vulnerability to water and drying characteristics, services and their locations.

The aims and functions of a prototype flood damage estimation tool are described, including the type of users aimed at, and the method of calculation, input data required and types of output delivered. The model is demonstrated on one case study of an actual building damaged by flooding and the predicted cost compared with the actual cost of reinstatement. A sensitivity analysis is made on the flood characteristic inputs.

The conclusions contend that that the prototype tool is worth developing to produce a useful way of predicting the costs of flood damage to individual buildings which will enable calculations to be made for assessing the cost-benefit analysis of installing flood mitigation/resilience measures to the building in order to protect it and its contents.
\end{abstract}

Keywords: Building construction, building flood vulnerability, cost-benefit analysis, critical infrastructure buildings, flood damage prediction, flood mitigation.

\section{INTRODUCTION}

Flooding in urban areas causes damage to peoples' homes and businesses and disrupts their lives. However, the effects of flooding can extend way beyond those directly affected by the water. For example, as a result of the July 2007 rising level of the River Severn around Tewkesbury and Gloucester in the UK, 5,000 homes and businesses were flooded, but due to the inundation of the Mythe Waterworks at Tewkesbury, 135,000 homes (over half the homes in Gloucestershire) were without drinking water for up to 17 days, and the flooding of an electricity substation rendered 48,000 homes without electricity for two days. Had the water risen by another $10 \mathrm{~cm}$, it would have overwhelmed the hastily erected flood barriers around the Walham substation with the result that 500,000 people would have been deprived of electricity for much longer.

This is the reason why one of the themes of the European Community Framework 7 research projects, FloodProBE, was to examine the effects of flooding on critical infrastructures in urban areas and to explore ways to predict the consequences of flood events. Critical infrastructures include not only the physical networks of cables, pipes and roads, but also the organisational networks of health, security and emergency services. The nodes within the 
networks are often in the form of buildings. These play an important role in protecting the equipment and personnel related to these networks (e.g. hospitals, fire stations, communications centres, power stations). However, the variety of designs and constructions of these buildings make it unrealistic to categorise them into meaningful types when considering their vulnerability to flooding. In order to be able to predict the effects of flooding and costs of reinstatement of these buildings, an individual approach needs to be taken, taking into account the specific characteristics of each building. The importance of these nodes, often referred to as hot spots, are critical.

This paper, based on research carried out in FloodProBE, is an extended and updated version of a paper accepted at the 2012 Sustainable Cities Conference in Ancona, Italy [1]. It examines the state of the art of estimation of damage to buildings on account of flooding and describes the development of a flood damage prediction tool that is aimed at individual buildings according to their construction types. In order to do this, the variables involved in damage estimation due to flooding of buildings are explored, the various existing damage methods are reviewed, and a prototype of an individual building damage prediction tool is outlined. The other indirect costs can only be estimated by the building users according to the severity of the flood effects on the building and with reference to the services they provide and nature of business and employment. This does not form part of the damage estimation with regard to the buildings, but can use this estimate to help to calculate these indirect costs.

\section{VARIABLES TO BE CONSIDERED}

Flood damage to buildings and contents are dependent on several variables in relation to the flood events. In addition to this, the type of building structure and construction, and the materials of which they are made have a big influence on the nature and extent of damage caused by the flood.

The flood event variables, their descriptions and literature that refers to them were examined by Gissing and Blong [2]. On their list they include: over-floor depth, velocity, rate of rise, debris, contaminants, frequency, duration and timing.

Variables relating to the building characteristics are mentioned by Soetanto and Proverbs, such as the materials that the building is constructed from, the drying characteristics of the materials and the condition of the building prior to being flooded [3]. To this can be added the structural system used, the types of building construction (the way that different materials are combined together), the planning of the spaces within the building (basements, level of ground floor above ground, etc.), the services and their positions within the building (electrical supply, air conditioning equipment, circuit boards, boilers, etc.).

A flood damage estimation tool that can deal with all these variables is likely to be very complex and difficult to manage, though oversimplification of the variables is likely to lead to inaccurate estimations. A balance must therefore be drawn between excessive complexity and accuracy, and ultimately usefulness.

\section{REVIEW OF THEORY AND PRACTICE OF FLOOD DAMAGE ESTIMATION RELEVANT TO BUILDINGS}

According to Hamann and Reese [4] a distinction must be made between the different scales of damage evaluation - macro, meso and micro scales (national, regional, local) for appropriate methodologies to be applied. However, Meyer and Messner [5] maintain that this is no longer strictly the case due to the development of more sophisticated damage data bases with object (micro scale) oriented assessments of flood damage being used for regional, and even 
national damage evaluation [6]. However, the reverse case in not appropriate - macro and meso scale damage evaluation method cannot be applied to the micro scale [7]. In keeping with this, this research is placed firmly in the lowest end of the micro scale, at the level of individual non-domestic buildings, including specifics of their construction methods and building materials used.

Much research has already been carried out on flood damage prediction methods [8-10], damage assessment [11-14], drying out and repair for residential buildings [15-17] with less research on non-domestic buildings [2]. Detailed investigation into the effects of flooding on a range of non-domestic constructions has been neglected.

On the subject of flood actions on buildings, Kelman and Spence [18] reviewed the current knowledge on effects of hydrostatic and hydrodynamic actions, as well as erosion, buoyancy and debris and chemical actions, and stressed their relative importance for direct flood damage estimation. Kreibich et al. [19] particularly concentrated on the significance of flow velocity in this respect, though noting that there appeared top be no link to monetary loss modelling. Some account of these actions should be taken at micro-scale investigations.

A review of current methods of building damage estimation was carried out in order to avoid repeating research and for building on the state of the art in this subject. The most relevant methods to this project are described briefly below, and their possible usefulness for individual non-domestic building flood damage estimation is assessed.

ANUFLOOD methodology. This methodology is Australia's most commonly used commercial flood damage estimation model. It uses potential stage-damage curves based on actual data from flooding in Australia and UK. Stage damage curves are categorised into different building sizes, types and uses. The commercial properties in the database are classified by size and value class that reflects the vulnerability to flood damage of the business's contents. The damage is only based on over-floor flood depth. As the data is based on averages, the damage to the individual properties often diverged considerably from the line of regression, hence the results tend to be inaccurate for individual buildings [2].

USACE velocity-damage curves. Floodwater velocity is rarely taken into account in calculating damage curves. The USACE (U.S. Army Corps of Engineers) Portland District velocity-based building collapse curves are one of the few that do [20]. These curves predict the collapse potential of buildings based on their types of construction, i.e. wood frame, masonry and concrete load bearing walls, steel frame, correlated with floodwater depth and floodwater velocity. The only output of the model is at what point the buildings are likely to collapse. There is no estimate of the range of partial damage to the building or costs of repair.

HAZUS-MH Flood Model - adaptation of earthquake model. This is used to characterise riverine and coastal flooding as a basis for damage and loss estimation in relation to buildings. This damage and loss capability includes a library of more than 900 damage curves for use in estimating damage to various types of buildings and infrastructure. The model uses estimates of flood depth along with depth/damage functions to calculate likely damage to buildings. The output is in the form of area-weighted estimates of damage as a percentage of replacement cost, at block or individual building scale [21]. However, the flood damage data and damage curves highest resolution is census block level so damage predictions are more reliable for large groups of buildings and unsuitable for use on individual buildings.

Stochastic methodology using Monte Carlo simulation. This stochastic methodology has been developed by Nadal et al. [22] that takes account of flooding hydrodynamics waves, turbulent bores, debris impacts, time dependent local soil scour as well as depth of 
flooding. The building vulnerability is modelled using analytical representations of the failure mechanisms of individual building components. The outputs estimate the average expected flood damage to individual buildings due to both floodwater depth and velocity on the basis of 10,000 hypothetical buildings. It shows that floodwater velocity can increase the damage to buildings by up to 100-190\% depending on the type of event. Although the study concentrates on reinforced concrete frame domestic buildings with infill concrete-block walls (including doors and windows), it could be applied to other structures using the same methodology, but lacks the flexibility to cope with combinations of different construction types and materials in individual buildings.

Damage and loss prediction based on an engineering evaluation system of building construction types. A study by Schwarz and Maiwald [23] at the Bauhaus University in Weimar uses an engineering evaluation system in order to predict damage and losses based on the vulnerability of building construction types. This takes into account the inundation level, flow velocity, duration and building type [19]. The buildings are classified into six types by material used for the construction and the structural system. The dataset included about 1220 residential buildings, most of substantial size with multiple accommodation units. The different building types were allocated to five flood vulnerability classes, with specification of the range of probable scatter into adjacent classes depending on factors such as building condition, quality of workmanship, types of building material. From this, damage curves were derived according to the depth of water. Although this is the most detailed investigation into flood damage to different building construction types, the predictions are however not sufficiently reliable for making precise damage predictions for individual buildings, particularly those featuring several different construction methods.

Despite a plethora of data from various parts of the world, it is evident that there is no established damage prediction tool for individual non-domestic buildings that can account in any detail for the different types of construction and materials used in their design. Unlike domestic buildings, non-domestic buildings often feature several different types of construction within the same premises. This makes categorisation of buildings simply according to construction types insufficient. It would therefore be a better approach to estimate damage at an elemental level - e.g. wall, floor, ceiling, services rather than a whole building level. This would give a 'menu' that could be used to select the particular construction types used for the various elements of an individual building, and the particular building materials used, thus leading to far greater accuracy in the estimates of damage and consequent costs for repair or replacement.

\section{STANDARD DAMAGE AND REPAIR PARAMETERS FOR FLOOD DAMAGE}

Although the existing models are not suited to the evaluation of individual buildings, there seems to be a general consensus on the parameters that influence flood damage, elegantly summarised by Nicholas et al. [24] in their conceptual model for flood damage (albeit for domestic properties). The model comprises two factors on which flood damage is dependent: the flood characteristics (floodwater depth, velocity, contaminant contents, flood duration) and the building characteristics (location, construction characteristics, nature of furnishings).

Flood damage assessment in the UK is normally based on the information from previous research contained in the 'Multi Coloured Manual' [25]. This provides standard approaches for calculating the flood damage for residential and non-residential properties, based on a large dataset of building stock and experience from major flood events. Although depth/damage 
curves are available, there are very few that can be considered to be applicable to critical infrastructure buildings, with the majority of the non-residential categories being of a commercial nature (shop or factory).

When determining the costs of repairing flood damaged buildings it is important to highlight that these costs are influenced by a multitude of factors, as discussed by Proverbs and Soetanto [26]; factors include technical considerations as well as commercial drivers such as cost or time of repair. Different repair strategies can be developed for the various individual building components (from the do-nothing case to the full replacement of a component) along with performance criteria on which to base decisions on the strategies to adopt. Proverbs and Soetanto suggest the following performance criteria: cost, quality, time and client satisfaction; and recommend that the various options for repair be assessed against these criteria.

Responses on several flooding scenarios set by the authors to cover a range of construction elements affected by floods (e.g. 'floodwater in contact with internal timber partition wall') were obtained from over 250 UK professionals working in the field of flood damage repair (mainly loss adjusters and surveyors but also consulting engineers, damage repair specialists, estate agents/housing associations and others). Based on these responses, benchmark repair strategies were developed for the reinstatement of flood damaged floors, walls, doors and windows, and utilities. The benchmark strategies are quite variable, ranging between the clean-up and the replacement of the whole element.

It was also noted that the most popular strategies were not necessarily the best in terms of cost, quality, time and satisfaction nor did they coincide with the benchmark strategy. A high level of disparity was found in current practice in the UK (as of 2004) and costs were mentioned as a barrier to the selection of the most efficient method by some respondents. In 2012, this variability in the restoration techniques used by different UK restorers remains, in spite of the experiences and lessons learned from recent floods, such as summer 2007. One initiative, to address this variability, is the update of PAS 64 [27], an industry-sponsored code of practice. This provides guidance and good practice for the restoration of a water damaged building from the initial incident to the point at which re-instatement and re-decoration can commence.

Another comprehensive source of guidance for flood affected properties is the CIRIA Report C623 [28]. It is noted that achieving the appropriate standard of repair goes beyond simply improving the resilience or design of the building, but requires the setting up of a proper regime for decontamination and drying the building, as well as a thorough post flood survey and assessment of future flood risk (see also Garvin and Kelly [29]). Three standards of repair level are proposed - little or none, low to medium, high - depending on the estimation of future flood risk.

For buildings supplying an essential service (critical infrastructure buildings or hotspot buildings) the guide recommends to increase its risk level to minimise potential future disruption of services. Repair measures are presented in detail for external walls, internal walls, floors and basements.

\section{DEVELOPMENT OF A PROTOTYPE DAMAGE PREDICTION TOOL FOR INDIVIDUAL BUILDINGS}

Damage predictions rely on accurate measurements of the effects of flooding on buildings of different constructions either from past events or as estimates based on technical information and laboratory tests on the different building materials. Owing to the wide range of building 


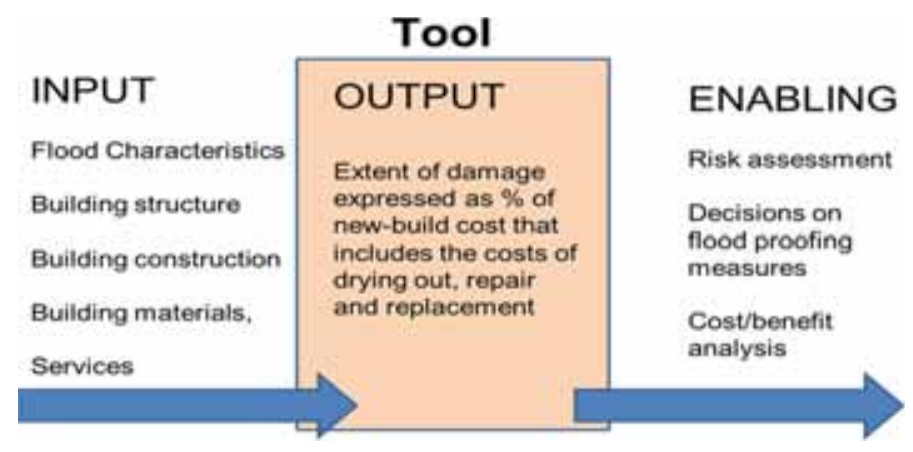

Figure 1: Building damage estimation tool principles.

types represented in non-domestic buildings, a great amount of detailed information will be required. This volume of data has the potential to make any calculations required to provide reliable estimates very complicated and user unfriendly unless a sophisticated system is devised to facilitate processing of the necessary inputs.

Most damage predictions at present only take into account flood depth (i.e. they are stagedepth predictions). This will not be sufficient in cases where high velocities and levels of pollution are anticipated. Therefore the tool should take into account these additional flood characteristics that cause different kinds of damage to buildings, such as velocity, duration, different types of pollution, e.g. oil, sewage, sediment, as well as debris. Therefore, the function of the proposed damage estimation tool is to predict the extent of damage to individual buildings depending on the severity of the flooding and the construction type of the building. The output of the tool should express the damage in cost form. This will enable calculations to be made in order to assess the cost-benefit analysis of installing flood mitigation measures to the building and/or its surroundings. A simple diagram of the principles of such a tool is presented in Fig. 1.

\subsection{Status of the tool as presented in this research}

It is important to stress that the aim of this research was to devise the principles and design a prototype of a flood damage prediction tool aimed at individual buildings and to test it in a limited way in order to gauge its effectiveness in principle. It was not the intention to produce a fully developed and verified tool that could be used in general practice. Further resources will be needed in the future to extend what has been achieved in this research in order to produce a comprehensive and robust tool for general applicability. A much larger choice of construction types and materials will need to be provided, more evaluation of the behaviour of these when subjected to flooding will be required, more refined damage/repair/replacement costs developed, and a comprehensive regime of testing against more detailed information from previous flood events should be carried out before the tool can be released for general use. Therefore, the tool as presented in this research should be regarded as a demonstration of the methodology for calculation of flood damage costs based on flood characteristics, detailed constructional information and associated damage factors. It will provide a springboard for the development of a fully functional tool that can be used for buildings of all types throughout Europe. 


\subsection{End users}

The tool has been designed for use by people with sufficient technical knowledge of the planning and construction of buildings in question, such as surveyors, architects and other building designers, quantity surveyors and property managers. The purpose of the tool is to enable building professionals who have no specialist knowledge of the effects of flooding on buildings to predict the cost of flood damage to individual buildings depending on the nature of the flood event and the individual constructional characteristics of a particular building. Other methods are needed for an estimation of the total direct and indirect costs incurred by damage to the contents of the building the consequences of loss of business, disruption of services, etc. The cost-benefit analysis of installing dry and wet proofing measures can be calculated in the following way.

The costs of installing various dry proofing solutions to the building can be determined by consultation with specialist firms that provide flood defence products, such as flood-control doors, air brick covers, non-return valves and temporary barriers. The tool can then be re-run with various solutions in place to gauge the reductions in damage and clean-up costs to the construction compared with the unprotected building. The reduced costs of damage to contents and disruption to business, services, etc. due to the protection afforded by the installed defences should then also be re-calculated. Depending on the expected frequency of the flooding the total average annual cost savings can be calculated and compared with the initial costs of installing flood defences.

The costs of wet proofing when repairing the building after flooding can be calculated by building professionals as a total cost of upgrading the specifications when replacing vulnerable materials and constructions with those that are water resistant. The tool can then be re-run with the 'improved' constructions, and the reduction in clean-up and repair costs can be calculated. The effects of the wet proofing on contents, business and services in case of a flood are also re-calculated. The total annual average reduction on damage costs can then be compared with the costs of installing wet proofing measures, again taking into account the flood frequency.

The tool is designed to be used by building professionals throughout Europe. Although the cost data is based on UK prices in 2012, there are conversion factors built in to the tool to make adjustments for the different building costs in the EU countries. The prices and the conversion factors would have to be updated regularly to reflect changes in these over time.

\subsection{Relevance to practice}

The aim was to produce a simple-to-use system that would encompass the elements of individual buildings likely to be affected by flood water, namely the basement and foundations, the external walls, the ground floor, the internal partitions including the internal doors and joinery, the external doors and windows, as well as the associated services such as electrics, plumbing and ventilation. The tool is aimed at building professionals with sufficient technical knowledge of the planning, construction and costing of buildings in question, such as architects, surveyors, facilities managers, quantity surveyors, and are comfortable with interpreting drawings and calculating areas of walls, floors, etc. The output of the tool expresses the damage in cost form. This will enable calculations to be made in order to assess the cost-benefit analysis of installing flood mitigation measures to the building and/or its surroundings. Verification of the prototype tool: checking the tool outputs with existing flood damage data. 
It is evident that much detailed data on the effects of flooding on different building materials depending on their use in different constructions will be required to make this model accurate in its predictions. The aim of this research project is to devise the calculations required by the tool to make predictions from input and stored data, using available technical data, and then to test the outcomes against real building flood damage records from past flood events.

\subsection{Data required}

The basic data required to be input into the tool by the user are:

- The flood characteristics of the event that is predicted

- Floodwater depth

- Velocity and debris

- Contaminant content

- Flood duration

- Identification of the main structural system

- The building divided by elements (external walls, floors, internal partitions, windows and doors, electrics, mechanical services, communications, etc.). Each element is analysed according to the materials used and the layering of them. To simplify the range of options, a list of typical constructions has been devised from which a choice can be made.

- Dimensions of walls, floors, etc. and numbers of doors and windows that are affected by the selected flooding event.

- Types of services, their positions and layout and the extent of these that are affected by the selected flooding event

The basic data that are contained in the tool are:

- A database of common elements of different constructions and materials

- A database of effects of flood damage to each construction or services and the \% newbuild cost incurred by clearing up costs, repair/replacement of the affected area of the construction or services, assuming clean water

- An additional cost to add for mechanically assisted drying

- An additional percentage calculated to add for pollution of different types, i.e. hazardous and non-hazardous

- An additional percentage calculated to account for the effects of high velocity and debris

- An additional percentage calculated to account for the duration of the flood

- An adjustment factor calculated for regional differences (i.e. different countries).

\subsection{Sources of data}

An important issue when collating the above was where reliable data could be sourced. The expert knowledge of architects and quantity surveyors was used, together with information from the reviewed literature.

The information about current materials and constructions used in buildings is easily available from technical publications and professional practical experience. The range of choice provided in this prototype tool was necessarily restricted but sufficient to cover some of the 
most common forms of building. The current new-build costs associated with these is also readily available from databases used by quantity surveyors and building price books. This is also the case for demolition, removal and disposal of debris. A quantity surveyor was employed to tabulate the new-build costs of each selected construction type and demolition, etc. costs. He also provided cost data obtained from industry sources relating to the cleaning and disposal of hazardous and non-hazardous pollution, as well as the costs of for mechanically assisted drying.

Assessment of the percentage of the new-cost allocated to the repair/replacement of the constructions is made by considering the extent of the damage according to the data from sources mentioned in Section 3 above, and the extent of demolition and removal/disposal of waste incurred. The estimation percentage allocated to pollution clean-up costs and disposal was made considering the ease of cleaning of the different types of material. The robustness of the constructions was the main factor is determining the effects of velocity and debris, and the absorption characteristics and permeability of the constructions were taken into account when estimating damage from duration of flood. These assessments were made using expert knowledge and any existing detailed data on materials performance relevant to flooding.

The correction factors for relative costs in different countries in the EU were derived from regularly produced comparison lists used by quantity surveyors and building estimators.

\subsection{Tool calculations and output}

The tool calculates the actual cost of flood damage to individual building elements according to their construction and materials, the types of services and the characteristics of the flooding. Table 1 indicates the measurement of characteristics of the flood event.

\subsection{User interface}

The tool has one page for inputting the required information, which is repeated for each building element and each type of construction. The selections are made from drop-down

Table 1: Measurement of characteristics of flood event.

\begin{tabular}{|c|c|c|}
\hline Characteristic & Type of measurement & Units of measurement \\
\hline Flood depth & $\begin{array}{l}\text { In } 0.3-\mathrm{m} \text { increments } \\
\text { Related to practical norms, repairs to walls are } \\
\text { made up to } 1.0 \mathrm{~m} \text { whenever the flood depth is } \\
\text { less than that; for flood depths above } 1.0 \mathrm{~m} \text {, the } \\
\text { whole height of the wall is repaired. } \\
\text { Repairs to windows for flood depth above } 0.6 \mathrm{~m} \\
\text { Repairs to lighting for flood depth above } 2.2 \mathrm{~m}\end{array}$ & $0.3-4.5 \mathrm{~m}$ \\
\hline Flood duration & 2 levels of measurement & $\begin{array}{l}\text { Up to } 24 \text { hours, more } \\
\text { than } 24 \text { hours }\end{array}$ \\
\hline $\begin{array}{l}\text { Velocity and } \\
\text { Debris content }\end{array}$ & Two levels of measurement & $\begin{array}{l}\text { None, significant } \\
\text { amount }\end{array}$ \\
\hline $\begin{array}{l}\text { Types of } \\
\text { pollution }\end{array}$ & Two levels of measurement & $\begin{array}{l}\text { Non-hazardous, } \\
\text { hazardous }\end{array}$ \\
\hline
\end{tabular}


menus for all of the variables that are needed in order to complete the calculations of cost. A list is compiled that displays all the calculations and the final total cost, taking into account all the information that has been entered. A screenshot of the inputting page is displayed in Fig. 2, with the information for one construction element (in this case internal partitions) added in.

The initial output, based on the database contained within the tool, predicts the cost of cleaning, repair or replacement and is expressed as a percentage of the new-build cost of each element. The percentage can be greater than $100 \%$, reflecting the costs of demolition and

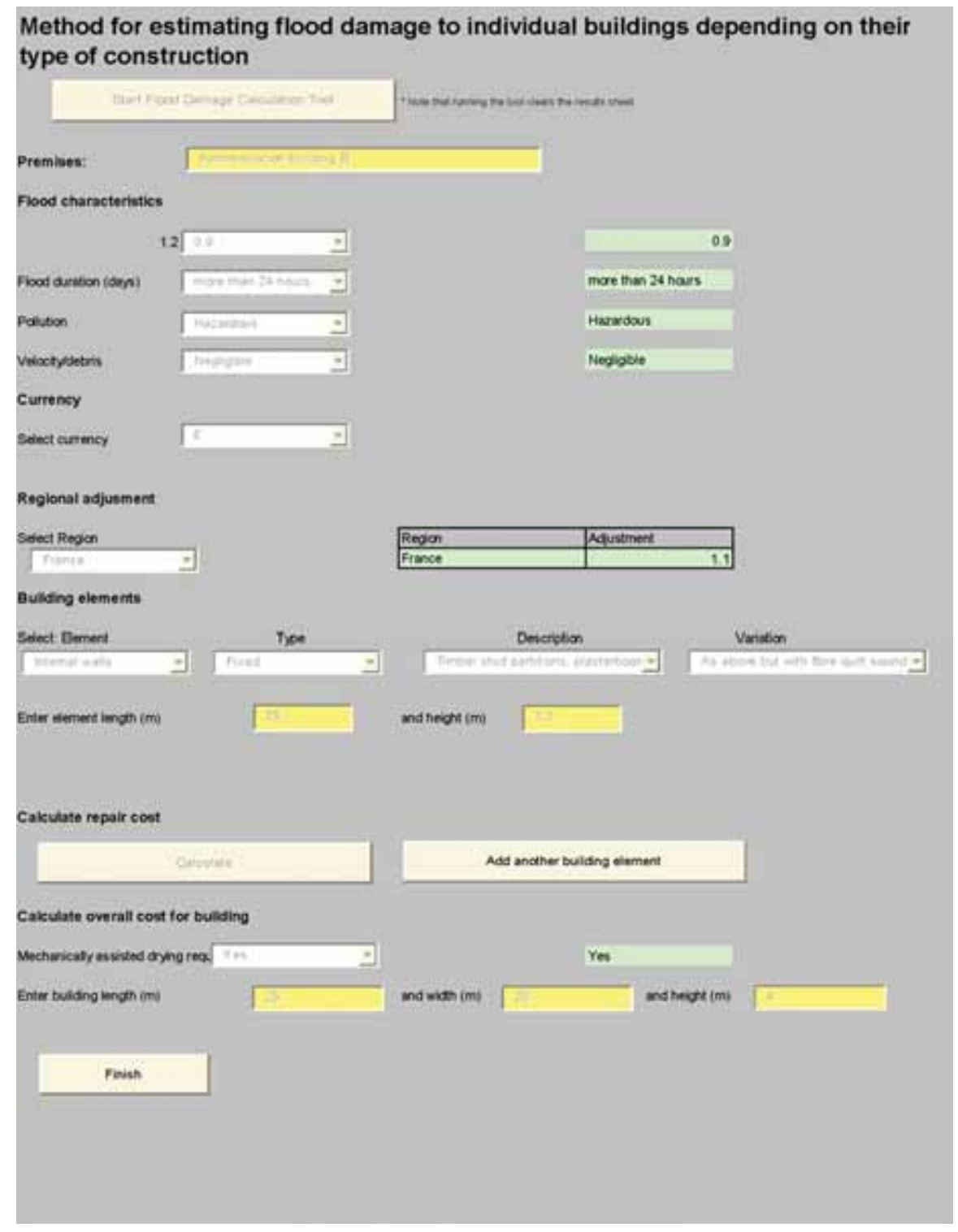

Figure 2: Input page of the tool. 
disposal of materials, as well as cleaning costs prior to rebuilding. Additional percentages are added for pollution clean-up and sterilization and mechanically assisted drying. An adjustment for regional factors (country, etc.) can then be made. An approximate indication of the actual cost of returning the building to use, depending on where it is and when the flooding occurs, can then be produced by the tool when it is combined with calculations using the areas, lengths or numbers of affected elements, the current or predicted rates of construction prices.

This tool can be used to compare the implications of flooding for different types of building construction, and to assess the value/cost of installing flood protection installations to the building to reduce the damage from future flooding.

\section{CASE STUDY}

Three case studies were carried out in order to gauge the accuracy of the predictions made by the tool. These were selected on the basis of being non-residential buildings of different sizes, constructions and uses. Case study 1 was a retail outlet with warehouse, case study 2 was an office building, and case study 3 was an engineering workshop. The damage and cost data on these three premises that were flooded in 2007 in the Sheffield area was supplied by AXA Insurance. As the data available was not sufficiently detailed to provide a full specification of the works undertaken and the quantities involved, so some assumptions had to be made. For the purposes of this paper Case Study 1 is described below to demonstrate how the tool works. This is followed by a summary of the results for the other case studies.

\subsection{Case study 1 , retail outlet with warehouse}

A U-shaped configuration of buildings and the adjacent yard area in Sheffield, South Yorkshire. One two storey retail/office building has a brick construction, with a pitched, tile clad roof, suspended timber intermediate floor and a concrete ground floor. To the rear of this building there is a single storeyed, brick constructed building with a pitched, tiled roof which accommodates the retail and wholesale trade counter and offices, whilst along the perimeter at the rear of the site, there is a steel portal framed warehouse, part metal part timber framemetal profile cladding over concrete block walls with roof cladding with plastic foam insulation boards linings and having a part mezzanine floor, which provides the main storage accommodation on the site. Total floor area approximately $700 \mathrm{~m}^{2}$.

On Monday 25 June 2007 some $35 \mathrm{~mm}$ of rainfall fell and water levels in the River Don rose remorselessly until this overtopped its banks and water spread over a wide area adjacent to the river, inundating numerous commercial and industrial sites.

Water from the river submerged all the yard area at the risk address, the carriageway outside and it accumulated to a depth of over half a metre in all the buildings on the site.

Although the water level subsided overnight, the premises was required to be sanitised and dried out, which involved stripping out areas of plasterwork, flooring, floor screeds and joinery work, together with some internal partitions. These elements were then required to be made good, along with the electrical installation, heating, the shop counter, sanitary equipment and decorative finishes. The entire warehouse floor needed to be replaced, and all the floors and affected areas of walls, doors and services in the shop and office needed to be repaired and replaced as necessary. The remaining surfaces of walls and floors throughout needed enhanced cleaning. The overall cost of the building work undertaken to $£ 82,741.70$. 
The model was run with the data from the size and construction characteristics of this building and the nature of the flood event. The calculations and results are summarised in Table 2:

Table 2: Model reinstatement cost prediction for case study 1 .

\begin{tabular}{|c|c|c|c|c|c|c|}
\hline Characteristic & \multicolumn{4}{|c|}{ Units of measurement } & \multicolumn{2}{|c|}{ Predicted flood event } \\
\hline Flood depth & & \multicolumn{3}{|l|}{$0.3-4.5 \mathrm{~m}$} & \multicolumn{2}{|l|}{$0.9 \mathrm{~m}$} \\
\hline Flood duration & & \multicolumn{3}{|c|}{ Up to 24 hours, more than 24 hours } & \multicolumn{2}{|c|}{ Up to 24 hours } \\
\hline Velocity and Debri & is content & \multicolumn{3}{|c|}{ None, significant amount } & \multicolumn{2}{|l|}{ None } \\
\hline Types of pollution & & \multicolumn{3}{|c|}{ Non-hazardous, hazardous } & \multicolumn{2}{|c|}{ Hazardous } \\
\hline $\begin{array}{l}\text { Element } \\
\text { construction }\end{array}$ & $\begin{array}{l}\text { Damage repair/ } \\
\text { Re-placement } \\
\text { and drying as } \\
\% \text { of new-build } \\
\text { cost }\end{array}$ & $\begin{array}{l}\text { Addition for } \\
\text { hazardous } \\
\text { pollution } \\
\text { clean-up }\end{array}$ & $\begin{array}{l}\text { Total \% } \\
\text { new-build } \\
\text { cost }\end{array}$ & $\begin{array}{l}\text { Square } \\
\text { metre, } \\
\text { length or } \\
\text { number } \\
\text { affected }\end{array}$ & $\begin{array}{l}\text { Current } \\
\text { new-build } \\
\text { cost in } £ \\
\text { (per } \mathrm{m}^{2}, \mathrm{~m} \\
\text { or number) }\end{array}$ & $\begin{array}{l}\text { Reinstatement } \\
\text { cost in } £\end{array}$ \\
\hline $\begin{array}{l}\text { External brick/ } \\
\text { block cavity wall } \\
\text { with rigid foam } \\
\text { insulation }\end{array}$ & 25 & 45 & 70 & 66 & 120 & 5544 \\
\hline $\begin{array}{l}\text { External solid } \\
\text { brick/block walls } \\
\text { (warehouse) }\end{array}$ & 62 & 154 & 216 & 75 & 35 & 5670 \\
\hline $\begin{array}{l}\text { Steel profiled } \\
\text { cladding }\end{array}$ & 52 & 55 & 107 & 76 & 97 & 7784.25 \\
\hline $\begin{array}{l}\text { Internal stud } \\
\text { and plasterboard } \\
\text { partitions }\end{array}$ & 89 & 15 & 104 & 30 & 45 & 1404 \\
\hline $\begin{array}{l}\text { Timber external } \\
\text { doors }\end{array}$ & 103 & 6 & 109 & 4 & 440 & 1918.4 \\
\hline $\begin{array}{l}\text { Timber internal } \\
\text { doors }\end{array}$ & 103 & 6 & 109 & 8 & 220 & 2877.6 \\
\hline $\begin{array}{l}\text { Concrete floor, } \\
\text { warehouse }\end{array}$ & 4 & 63 & 67 & 400 & 84.5 & 22646 \\
\hline $\begin{array}{l}\text { Concrete floor, } \\
\text { office }\end{array}$ & 4 & 63 & 67 & 200 & 84.5 & 11323 \\
\hline Steel cargo doors & 4 & 22 & 26 & 2 & 2500 & 1300 \\
\hline Piped services & 5 & 8 & 13 & 200 & 12.2 & 317.2 \\
\hline $\begin{array}{l}\text { Wired services } \\
\text { office/shop }\end{array}$ & 125 & 8 & 133 & 200 & 32.28 & 8586.48 \\
\hline $\begin{array}{l}\text { Wired services } \\
\text { warehouse }\end{array}$ & 120 & 8 & 128 & 400 & 47.75 & 14976 \\
\hline \multirow{2}{*}{$\begin{array}{l}\text { Heating } \\
\text { installation }\end{array}$} & 21 & 32 & 54 & 204 & 48 & 2578.5 \\
\hline & & & & & Total & $86,925.43$ \\
\hline
\end{tabular}


Table 3: Sensitivity in the overall repair cost to the flood characteristics.

\begin{tabular}{lllcc}
\hline Flood duration & Flow velocity & Pollution & Repair cost (£) & Change from base (\%) \\
\hline Less than 24 hours & Negligible & Hazardous & $86,925.43$ & Base - Case Study 1 \\
More than 24 hours & Negligible & Hazardous & $93,194.93$ & $7.2 \%$ \\
Less than 24 hours & Negligible & Non-Hazardous & $60,162.89$ & $-30.8 \%$ \\
Less than 24 hours & High* & Hazardous & $92,672.68$ & $6.6 \%$ \\
Less than 24 hours & High* & Non-Hazardous & $65,910.14$ & $-24.2 \%$ \\
More than 24 hours & Negligible & Non-Hazardous & $66,432.39$ & $-23.6 \%$ \\
More than 24 hours & High* & Non-Hazardous & $72,179.64$ & $-17 \%$ \\
More than 24 hours & High* & Hazardous & $98,942.18$ & $13.8 \%$
\end{tabular}

*The database is currently incomplete for the additional repair cost due to high-flow speed.

The predicted figure of $£ 86,925.43$ compares favourably with the actual cost of $£ 82,741.70$, which is measured at a level of $95 \%$ accuracy.

In case study 2, a four storey office building constructed with a steel frame and brickwork cladding with a total floor area of approximately $3716 \mathrm{~m}^{2}$, the predicted figure of $£ 246,504$ compared unfavourably with the actual cost of $£ 386,347$ for the building reinstatement. The prediction presents an unacceptable accuracy of only $63 \%$. Further investigation will be needed to find out the sources of these discrepancies. However, due to insufficiently detailed damage cost data on individual constructions and materials, this has proved difficult to carry out, so the reasons remain unexplained at this point.

In case study 3 , a single storey engineering workshop of about $780 \mathrm{~m}^{2}$, constructed with a portal frame with brick infill, the predicted cost of clear-up and reinstatement of $£ 102,840$ compares favourably with the actual cost of $£ 90,070$, which is measured at a level of $88 \%$ accuracy.

\subsection{Sensitivity analysis}

A sensitivity analysis was undertaken to estimate the level of dependency of the results on the values of various flood parameters and thereby provide some basis for assessing which uncertainties in the input data have most weight on the final results. The Case Study 1 was chosen for the sensitivity analysis. The variables flood duration, flood velocity and pollution were changed to calculate the sensitivity of the overall repair cost to the characteristics of the flood. The overall repair costs obtained from this analysis are summarised in Table 3.

Table 3 shows that the repair cost is most sensitive to the type of pollution considered (hazardous/non-hazardous), although it should be noted that the input database on the cost for high-flow speed is still incomplete at this stage for many of the building elements. It can be seen in this example that considering pollution as non-hazardous would reduce the overall cost of repair by over $30 \%$. Further sensitivity analysis is recommended at later stages of development of the tool.

\section{CONCLUSIONS AND RECOMMENDATIONS}

The devastating effects of flooding on critical infrastructures in urban areas, and how to mitigate these, was the main focus of the EC 7th Framework Programme entitled FloodProBE. Important components of critical infrastructures are the buildings used to house equipment 
and personnel. The aim of the research described in this paper was to identify the risks to these important buildings posed by flooding, and to develop the methodology for a practical flood damage estimation tool that is particularly designed to calculate the extent and costs of damage of individual infrastructure buildings according to the construction of their various elements. The tool will also be suitable for use on any other type of building, and particularly useful for those built with a variety of construction systems.

The main result of this research is a demonstration, through the development of the tool, that it is possible to extend the range of flood damage prediction methods to the micro level of individual buildings taking into account the details of their construction. Up until now, it has been difficult for owners or designers of buildings to use available aggregated damage curves to accurately assess the likely damage from flooding to their buildings. The existing building damage assessment methods concentrated on making generalised predictions based on rudimentary categorisation of construction types, to which individual buildings rarely conform in detail. By assessing damage at a hierarchical element/construction/material level, more accurate estimations of the costs of building reinstatement after flood damage can be achieved. The prototype tool uses a simple-to-use calculation method, requiring inputs from the user that are related to particular buildings and are readily available and familiar to any construction professional. The tool lends itself to repeated runs for gauging the costs of damage caused by various flood scenarios and levels of protection. This facilitates the calculation of the level of risks to the existing buildings, and provides a useful basis on which to calculate the costs and effectiveness of possible flood protection and proofing measures that are being considered. This prototype tool provides a basis for further development to devise a comprehensive, tested method of calculating damage costs to individual buildings throughout Europe. The tool, when it has been further developed to a fully functional stage, can also be used as a design aid for new buildings, to compare the vulnerability to flooding of various construction options, particularly in the cases where wet proofing is introduced. This is particularly valuable to inform the design of buildings to be constructed in areas with a real risk of flooding, such as those built on or adjacent to floodplains or vulnerable coastal areas, or even in areas liable to slow water run-off.

There are several limitations to the tool in its prototype stage. The flood damage estimation tool relies on a range of expert assessments of the scale of damage and costs of repair/replacement of a wide range of building constructions. These assessments can be made more robust by repeated testing against real situations, both in the laboratory and in real life as experienced in past flood events. In order to do this, much more specific information of flood events is required, including detailed data about the effects of different flood characteristics on different building constructions and materials, and itemised costs of necessary repair/replacement works. It has proved difficult to gain this level of detail during this research, partly due to issues of confidentiality, to lack of detailed records of past events, and division of responsibilities during and after the event. It would be easier to gain this required level of detail in the data if cases could be tracked in real time, during and after a flood event, thus eliminating the problems of retrieving information sometimes years after the flooding and repair works. Considerable time will have to be allowed for this process.

The range of different constructions and materials presented by the prototype tool is very limited compared with what is available and used throughout Europe. In order for the tool to be widely applicable, a far greater choice of these should be offered in the menus. To provide this requires a major exercise in cataloguing and assessing typical construction methods and 
materials in the various countries. More research will also be needed to gauge the effect of flooding on these and the extent of repair/replacement required to reinstate them. However, the new-build costs for every type of building material and construction in every country are readily available for use in the calculations. The introduction of new building materials and their combination in new construction systems over time also require additional data to be added to the tool to keep it relevant to present and future building practice.

The further expansion and refinement of this prototype tool should therefore be regarded as an on-going process, and further funding should be sought in order to develop it to a stage where it can be offered to the building professionals. Options should then be considered of how to generate some income from the distribution of the tool that will enable on-going revision, expansion and up-dating to take place. Despite this, the tool should be made widely available at little or no cost to the user, in order to encourage its use in the aim of increasing resilience in the essential urban infrastructures to flood events.

\section{ACKNOWLEDGEMENT}

The work described in this publication was supported by the European Community's Seventh Framework Programme through the FloodProBE project. This paper reflects the authors' views and not those of the European Community.

\section{REFERENCES}

[1] Walliman, N., Ogden, R., Baiche, B., Tagg, A. \& Escarameia, M., Development of a tool to estimate individual building vulnerability to floods. The Sustainable City VII Urban Regeneration and Sustainability - WIT Transactions on Ecology and the Environment Series, Vol. 155, WIT Press: Southampton, 2012. Available at www.witpress.com

[2] Gissing, A. \& Blong, R., Accounting for variability in commercial flood damage estimation. Australian Geographer, 35(2), pp. 209-222, 2004. doi: http://dx.doi. org/10.1080/0004918042000249511

[3] Soetanto, R. \& Proverbs, D.G., Impact of flood characteristics on damage caused to UK domestic properties: the perceptions of building surveyors. Structural Survey, 22(2), pp. 95-104, 2004. doi: http://dx.doi.org/10.1108/02630800410538622

[4] Hamann, M. \& Reese, S. Wertermittlungen und Schadensanalyse als Instrumente für die Küstenschutzplanung in Schleswig-Holstein. Bremer Beiträge zur Geographie und Raumplanung, 36(S), pp. 139-147, 2000.

[5] Meyer, V. \& Messner, F. National Flood Damage Evaluation Methods: A Review of Applied Methods in England, the Netherlands, the Czech Republic and Germany. UFZ-Discussion Papers UFZ-Umweltforschungszentrum. Leipzig-Halle Department Ökonomie: Leipzig, 2005.

[6] Hall, J.W., Dawson, R.J., Sayers, P.B., Rosu, C., Chatterton, J.B. \& Deakin, R., A methodology for national-scale flood risk assessment. Water and Maritime Engineering, 156, pp. 235-247, 2003. doi: http://dx.doi.org/10.1680/wame.2003.156.3.235

[7] Messner, F., Penning-Rowsell, E., Green, C., Meyer, V., Tunstall, S. \& van der Veen, A., Evaluating flood damages: guidance and recommendations on principles and methods. T9-06-01, FLOODsite Project - Integrated Flood Risk Analysis and Management Methodologies, 2007.

[8] Kreibich, H. \& Thieken, A.H., Assessment of damage caused by high groundwater inundation. Water Resources Research, 44(9), pp. 6621-39, 2008. doi: http://dx.doi. org/10.1029/2007WR006621 
[9] Bočkarjova, M., Steenge, A.E. \& van der Veen, A., On direct estimation of initial damage in the case of a major catastrophe: derivation of the "Basic equation". Disaster Prevention and Management, 13(4), pp. 330-337, 2004. doi: http://dx.doi. org/10.1108/09653560410556555

[10] Jonkman, S.N., Bočkarjovab, M., Kokc, M. \& Bernardinid, B., Integrated hydrodynamic and economic modelling of flood damage in the Netherlands. Ecological Economics, 66(1), pp. 77-9015, 2008. doi: http://dx.doi.org/10.1016/j.ecolecon.2007.12.022

[11] Soetanto, R. \& Proverbs, D.G. Impact of flood characteristics on damage caused to UK domestic properties: the perceptions of building surveyors. Structural Survey, 22(2), pp. 95-104, 2010. doi: http://dx.doi.org/10.1108/02630800410538622

[12] Nicholas, J., Holt, G.D. \& Proverbs, D.G., Towards standardising the assessment of flood-damaged properties in the UK. Structural Survey, 19(4), pp. 163-172, 2001. doi: http://dx.doi.org/10.1108/02630800110406667

[13] Proverbs, D.G., Nicholas, J. \& Holt, G.D., Surveying flood damage to domestic dwellings: the present stage of knowledge. The Royal Institution of Chartered Surveyors Research Foundation Paper Series, 3(8), 2000.

[14] Elmer, F., Thieken, A.H., Pech, I., Kreibich, H., Influence of flood frequency on residential building losses. Natural Hazards Earth System Sciences, 10, pp. 2145-2159, 2010. doi: http://dx.doi.org/10.5194/nhess-10-2145-2010

[15] BRE Digest, Repair and Renovation of Flood-Damaged Buildings, Building Research Establishment: Watford, 1984.

[16] BRE, Dealing with Flood Damage, Building Research Establishment: Watford, 1991.

[17] Kidd, B., Tagg, A., Escarameia, M., von Christierson, B., Lamond, J. \& Proverbs, D., Guidance and Standards for Drying Flood Damaged Buildings. Signposting current guidance - BD2760. CIRIA, Construction Industry Research and Information Association: London, 2010.

[18] Kelman, I. \& Spence, R., A flood failure flowchart for buildings. Municipal Engineer, 156(Sept), pp. 207-214, 2003. doi: http://dx.doi.org/10.1680/muen.2003.156.3.207

[19] Kreibich, H., Porith, K., Seifert, I., Maiwald, H., Kunert, U., Schwarz, J., Merz, B. \& Thieken, A., Is flow velocity a significant parameter in flood damage modelling? Natural Hazards and Earth Systems Sciences, 9(5), pp. 1679-1692, 2009. doi: http://dx.doi. org/10.5194/nhess-9-1679-2009

[20] USACE, Business Depth-Damage Analysis Procedures. Research Rep. 85-R-5, USACE, Engineering Institute for Water Resources: Alexandria, VA, USA, 1985.

[21] Scawthorn, C., Flores, P., Blais, N., Seligson, H., Tate, E., Chang, S., Mifflin, E., Thomas, W., Murphy, M., Jones, C. \& Lawrence, M., HAZUS-MH Flood loss estimation methodology. II. Damage and loss assessment. Natural Hazard Review, 7(72), pp. 72-82, 2006. doi: http://dx.doi.org/10.1061/(ASCE)1527-6988(2006)7:2(72)

[22] Nadal, N., Zapata, R., Pagán, I., López, R. \& Agudelo, J., Building damage due to riverine and coastal floods. Journal of Water Resources, Planning and Management, 136(3), pp. 327-336, 2010. doi: http://dx.doi.org/10.1061/(ASCE)WR.1943-5452.0000036

[23] Schwarz, J. \& Maiwald, H., Damage and loss prediction model based on the vulnerability of building type. 4th International Symposium on Flood Defence: Managing Flood Risk, Reliability and Vulnerability, Toronto, Ontario: Canada, 2008.

[24] Nicholas, J., Holt, G.D. \& Proverbs, D.G., Towards standardising the assessment of flood damage properties. UK, Structural Survey, 19(4), pp. 163-172, 2001. doi: http:// dx.doi.org/10.1108/02630800110406667 
[25] Penning-Rowsell, E.C., Johnson, C., Tunstall, S., Tapsell, S., Morris, J., Chatterton, J., Coker, A. \& Green, C., The Benefits of Flood and Coastal Defence: Techniques and Data for 2003. Flood Hazard Research Centre, Middlesex University: London, 2003.

[26] Proverbs, D.G. \& Soetanto, R., Flood Damaged Property, Wiley: Chichester, U.K., 2004.

[27] BSI (British Standard Institution), PAS 64Professional Water Damage 122 Flood Hazard: Impacts and Responses for the Built Environment, BSI: London, 2005.

[28] Garvin, S., Reid, J. \& Scott, M., CIRIA Report C623 - Standards for the Repair of Buildings Following Flooding, CIRIA: London, 2005.

[29] Garvin, S. \& Kelly, D., Flood repair standards for buildings. Advances in Urban Flood Management, eds. R. Ashley, S. Garvin, E. Pasche, A. Vassilopoulos \& C. Zevenbergen, Taylor and Francis: London, 2007. 